\title{
Comparison of Holstein-Friesian and Norwegian Red dairy cattle for estrus length and estrous signs
}

\author{
G. Sveberg, ${ }^{1}$ G. W. Rogers, † J. Cooper,† A. O. Refsdal,† H. W. Erhard, $¥ \S$ E. Kommisrud,\# F. Buckley,॥ \\ A. Waldmann, П and E. Ropstad* \\ *Department of Production Animals Clinical Sciences, Faculty of Veterinary Medicine and Biosciences, Norwegian University of Life Science, \\ $\mathrm{N}-0033$ Oslo, Norway \\ †GENO Breeding and AI Association, N-2317 Hamar, Norway \\ $\ddagger$ AgroParisTech, UMR791 Modélisation Systémique Appliquée aux Ruminants, 75005 Paris, France \\ §INRA, UMR791 Modélisation Systémique Appliquée aux Ruminants, 75005 Paris, France \\ \#Faculty of Education and Natural Sciences, Hedmark University College, N-2418 Elverum, Norway \\ $\|$ Animal and Bioscience Research Department, Animal and Grassland Research and Innovation Centre, Teagasc, \\ Dairy Production Research Centre, Moorepark, Fermoy, Co. Cork, Ireland \\ IDepartment of Reproductive Biology, Institute of Veterinary Medicine and Animal Sciences, Estonian University of Life Sciences, \\ 51014 Tartu, Estonia
}

\section{ABSTRACT}

This study addressed the effect of breed on estrus length and estrous behavior by observing 20 HolsteinFriesian (HF) and 20 Norwegian Red (NRF) cows on an outdoor wood-chip pad through 1 estrous cycle $(22$ d). Detailed behavioral data were collected by continuous $(24 \mathrm{~h})$ video monitoring of all cows. Accurate estimation of duration of estrous periods, behavioral signs (sum per period and counts per hour), and duration and number of sexually active groups were reported through all stages of mount estrus (prestand, standing estrus, and poststand). These dependent variables were analyzed with a basic statistical model that included fixed effects for breed and lactation group. Other independent variables (milk yield, body condition score, and number of cows in standing estrus) were added to the basic model one by one and included in an expanded model if they had an effect on the respective dependent variables. Estrus duration was considerably shorter in HF compared with NRF cows for all the major periods: mount estrus (11.2 \pm 3.0 vs. $21.3 \pm 2.7$ h), standing estrus $(7.1 \pm 1.4$ vs. $11.7 \pm 1.3 \mathrm{~h})$, mounting period $(6.9 \pm 2.7$ vs. $18.2 \pm 2.4 \mathrm{~h})$, and mounted period $(9.2 \pm 2.8$ vs. $17.5 \pm 2.6 \mathrm{~h})$. Additionally, the NRF cows spent more time in sexually active groups $(36.1 \pm 4.0$ vs. $17.6 \pm 4.8 \%)$ during standing estrus compared with HF cows. The NRF cows participated in a greater number of sexually active groups $(9.6 \pm 1.3$ vs. $5.5 \pm 1.3)$ with longer average duration $(0.42 \pm 0.04$ vs. $0.20 \pm 0.04 \mathrm{~h}$ ) and continued to be more active in these groups through late stages of estrus (poststand)

Received September 27, 2014.

Accepted December 7, 2014.

${ }^{1}$ Corresponding author: guro.sveberg@tine.no compared with the HF breed. Mounting activity differed between breeds as NRF mounted more times in total $(46.3 \pm 6.2$ vs. $18.1 \pm 6.3)$ and per hour $(2.6 \pm 0.4$ vs. $1.5 \pm 0.5)$ during mount estrus. In addition, NRF tended to express the primary estrous sign, standing when mounted, more often during standing estrus (32.4 \pm 5.0 vs. $18.5 \pm 5.2$ ). The HF initiated more unsuccessful mounts $(1.6 \pm 0.3$ vs. $0.6 \pm 0.3)$ per hour than did NRF during mount estrus. A significant effect of milk yield was demonstrated only on this behavior. For other estrous signs, HF cows initiated chase-up (2.0 \pm 0.5 vs. $0.5 \pm 0.4)$ and anogenital sniff $(3.7 \pm 0.6$ vs. 2.0 $\pm 0.5)$ more frequently (counts per hour), whereas NRF expressed more total head butt behavior ( $32.3 \pm 4.7$ vs. $14.2 \pm 4.8$ ) during mount estrus. Body condition score had a significant effect on receptive behavior. Measures of estrus duration, sexually active group activity, and behavior related to estrus should be subjected to larger studies for improved heat detection and possible implementation in breeding programs.

Key words: estrous length, breed, fertility

\section{INTRODUCTION}

Impaired health and fertility are major obstacles for efficient management, and failure to detect estrus is regarded as one of the most important factors contributing to reproductive failure in dairy herds (Senger, 1994; Van Vliet and van Eerdenburg, 1996). Animal behaviorists report significant side effects on behavior and welfare, which is thought to be due in part to the several decades of intense selection for increased milk production (Jensen et al., 2008; Boichard and Brochard, 2012). Breeding programs focusing on milk yield have resulted in substantially increased milk yield and reduced fertility of the predominant dairy breed, 
Holstein Friesian (HF), over the last 40 yr (Dobson et al., 2008; Walsh et al., 2008). Milk yield is reported to influence estrous behavior (Lopez et al., 2004; Cutullic et al., 2012), and breed effects on production and fertility traits are described in the literature (Walsh et al., 2008). The influence of breed on estrous expression, however, is poorly documented.

For dairy breeds such as Norwegian Red (NRF) and Swedish Red cattle, fertility traits have been included in the breeding programs for the last $40 \mathrm{yr}$ (Refsdal 2007), with documented and sustained fertility despite increasing milk yield (Philipsson and Lindhé, 2003). Estrous expression in Scandinavian Red cows, however, is not well documented in the literature. Most knowledge has relied on the many studies reporting behavioral signs in HF cows (Van Vliet and van Eerdenburg, 1996; Kerbrat and Disenhaus, 2004). Hammond (1927), Trimberger (1948), and Hurnik et al. (1975) found no differences in estrous expression between breeds, but few recent studies address these questions (Cutullic et al., 2009), and several of them compare beef breeds (Rae et al., 1999; Landaeta-Hernández et al., 2004).

Mounting behaviors are frequently used in visual observation, they are required for different heat detection devices such as tail paint and automatic mount detectors, and they represent proceptive and receptive patterns that characterize specific periods in estrus (Sveberg et al., 2011). Over the past 30 to 50 yr, the percentage of animals in estrus that stand to be mounted has declined from 80 to $50 \%$, and the duration of standing estrus has declined from 15 to $5 \mathrm{~h}$, according to a review of different studies by Dobson et al. (2008). The same authors report that the duration of total number of estrous signs has not declined in the same period, suggesting a change from primary to other estrous signs in the HF breed. The use of concrete as flooring impairs mount activity, stand activity, and estrus duration (Britt et al., 1986), and an increase in diseases such as lameness is reported to decrease intensity of estrous signs (Dobson et al., 2008). A greater number of cows express mount estrus than standing estrus (Hurnik et al., 1975; Sveberg et al., 2011); consequently, more focus on the mount period would be preferable. Nevertheless, few other studies are based on continuous observations through complete estrous cycles (Rodtian et al., 1996), reporting detailed data of behaviors and duration of specific estrous periods (Hurnik et al., 1975).

Løvendahl and Chagunda (2009) and Løvendahl et al. (2009) report higher heritability for estrus activity traits and days to first estrus compared with traditional fertility traits and discuss the possibility of including estrous expression in future breeding programs. Public perception and opposition may demand less use of hor- monal synchronization protocols in future dairy management. Consequently, knowledge of estrous expression and possible breed differences may prove increasingly important in contemporary dairy production.

The objective of the present study was to determine the effect of breed on estrus length and estrous signs by observing $20 \mathrm{HF}$ and $20 \mathrm{NRF}$ cows continuously through 1 complete estrous cycle.

\section{MATERIALS AND METHODS}

All procedures were carried out under experimental license issued by the Irish Department of Health and Children, in accordance with the European Communities (Amendment of Cruelty to Animals Act 1876) Regulations 2005.

\section{Animals, Housing, and Management}

Twenty Holstein-Friesian cows from the study of Sveberg et al. (2011) and 20 Norwegian Red cows, all at the Teagasc Moorepark Ballydague research farm in Ireland, were observed continuously for $22 \mathrm{~d}$, beginning on April 18, 2006. The 2 groups of cows were each housed on a 16- $\times 24-\mathrm{m}$ outdoor pad with wood-chip flooring. The groups were separated by a $2-\mathrm{m}$-wide corridor, and electrical fences were used to prevent physical contact. Halfway through the study, the groups changed location so that the 2 groups were housed on both paddocks. The cows were offered freshly cut pasture and $2.6 \mathrm{~kg}$ of concentrate DM per cow per day (Sveberg et al., 2011). Cows were in first to sixth parity, with a frequency distribution by parity of $8,3,2,4,2,1$ and $8,4,1,4,0$, 3 for $\mathrm{HF}$ and NRF, respectively. Body condition score (Lowman et al., 1976) was recorded monthly postpartum and $14 \mathrm{~d}$ before the start of the study. Body weights were recorded weekly. Cows included in the study were required to have no abnormal signs in the reproductive tract upon examination by ultrasound, lameness scores of $\leq 2$ (Sprecher et al., 1997), BCS of at least 2.5 (Lowman et al., 1976), and be at least 5 wk postpartum (mean $63 \mathrm{~d}$; range 44 to $84 \mathrm{~d}$ for $\mathrm{HF}$ and mean $65 \mathrm{~d}$; range 42 to $85 \mathrm{~d}$ for NRF). Reproductive organs were examined by ultrasound (Sveberg et al., 2011) between d 28 and 35, and between d 50 and 60 postpartum to reveal reproductive disorders and evidence of ovarian cyclicity. Individual cow milk yields were recorded using electronic milk meters (Dairymaster, Causeway, Co. Kerry, Ireland) and twice-daily milk samples from each cow were preserved and frozen for later measurements of progesterone concentration by enzyme immunoassay (Waldmann, 1993), modified by using the second antibody coating technique (Waldmann, 1999; Sveberg et al., 2011). Function of the corpus luteum was confirmed 
by progesterone profiling, characterized by successive waves of increasing and decreasing progesterone values. Standing estrus or mount estrus was confirmed by low milk progesterone concentrations $(<2.5 \mathrm{ng} / \mathrm{mL})$ during this period.

\section{Definitions}

The definitions of stages of estrous cycle were as follows (Sveberg et al., 2011, 2013):

1. Mount estrus (estrus): the interval from the first to the last mount engaged in by the cow going through standing estrus or cyclic nonstanding cows with confirmed low progesterone concentrations during this period. A minimum of 2 mounts within $24 \mathrm{~h}$ was required.

2. Standing estrus (true estrus): the interval between the first and last standing events, at which the cow remains stationary when mounted.

3. Prestand: the period between the start of the mount estrus and the start of the standing estrus.

4. Poststand: the period between the end of the standing estrus and the end of the mount estrus.

5. Mounting period: the interval from the first to the last mounting of another individual by the animal passing through estrus (Hurnik et al., 1975).

6. Mounted period: the interval from the first to the last occurrence of being mounted by another individual of the animal passing through estrus (Hurnik et al., 1975).

Behavioral definitions (Sveberg et al., 2011, 2013) were as follows:

1. Primary estrous sign: the cow remains stationary when mounted.

2. Secondary estrous signs: mount, attempt to mount, anogenital sniff, chin rest, chase up, head butt, and play rub.

3. Other social behaviors: push away and body butt.

4. Sexually active group 3-5 (SAG 3-5): cow participating in a minimum of 1 estrous behavior per 5 min with its sexually active partner(s) while staying within $3 \mathrm{~m}$ (2 cow lengths) of the partner(s) for at least 5 min. All further mention of sexually active groups in this paper is based on the SAG 3-5 measure.

Cows initiating and receiving behaviors were identified, except for head butt and play rub, as it was not possible to differentiate between initiator and receiver of these 2 mutual behaviors.

\section{Behavior Recording and Data Management}

Four cameras (Axis 211, Axis Communications, Lund, Sweden) covered the area of 2 parallel rectangular outdoor pads, each containing $20 \mathrm{HF}$ or $20 \mathrm{NRF}$ cows. Two cameras covered each pad area and were placed $3.5 \mathrm{~m}$ above the ground at both corners of the respective long sides opposite to the corridor. To allow continuous video surveillance, artificial white light was used at night. Individual identification codes were painted on the neck, flank, and upper leg of each cow to facilitate identification.

Videos were analyzed retrospectively and the resulting data were entered into a database (Sveberg et al., 2011). The researcher analyzing the video recordings had no knowledge of the estrous cycle stage of the individual animals. Cows were observed continuously through 1 estrous cycle $(22$ d), until all cows either had shown a regular cyclic change in progesterone concentrations and mount estrus when progesterone was $<2.5 \mathrm{ng} / \mathrm{mL}$, or only a regular cyclic progesterone profile without mount estrus. Estrous signs, other social behaviors, and sexually active groups were recorded throughout the study period. Behavioral observations were continued for $24 \mathrm{~h}$ after the last mount observation of the last cow expressing mount estrus. Records from $1 \mathrm{~d}$ in which cows did not express standing estrus on either the preceding or the following day and had progesterone levels of at least $2.5 \mathrm{ng} / \mathrm{mL}$ were used for comparisons during nonestrus. The periods $24 \mathrm{~h}$ before and after mount estrus were divided into shorter 3-h intervals (Roelofs et al., 2005; Sveberg et al., 2011) and analyzed accordingly.

\section{Statistical Analyses}

Dependent variables for duration of estrus and estrous stages and behaviors related to estrus were analyzed with a basic statistical model that included fixed effects for breed of cow and lactation group (lactation 1 or 2 and greater) as independent variables. All analyses were done using the GLM procedure of SAS (ver. 9.3; SAS Institute, Inc., Cary, NC).

Duration of mount estrus, duration of standing estrus, duration of the prestand period, duration of the poststand period, duration of the mounting period, and duration of the mounted period were all used as dependent variables. Total number and duration of sexually active groups, time spent in sexually active groups, total number and frequencies for primary estrous signs, secondary estrous signs, and other social behaviors 
were all included as dependent variables. The dependent variables were from a single complete estrous cycle for each cow.

Lactation number was included in the basic model, together with breed, to avoid any effect of unbalanced study groups with regard to parity and as a potential source of variation in the traits being investigated. Four $\mathrm{HF}$ cows and $1 \mathrm{NRF}$ cow were not cyclic and 1 additional HF cow was excluded because the duration of her estrous cycle was $25 \mathrm{~d}$ and consequently observations for a full estrous cycle were incomplete. Additionally, due to electrical power failure during standing estrus for 3 out of $19 \mathrm{NRF}$ cows, behaviors were not observed completely and these cows were excluded from analysis of single behaviors and sexually active groups. The inability to include all cows in analyses created unbalance across parities so it was important to include lactation number in the model. Possible interactions between breed and lactation number were analyzed for all dependent variables. The independent variables milk yield, BCS, and number of cows in standing estrus were added to the basic model one by one and included in an expanded model if they had a significant effect $(P$ $<0.05)$ on the dependent variables. These additional independent variables were included to discern possible mechanisms for breed differences and to study effects on estrous behavior and estrus length reported in the literature (Hurnik et al., 1975; Lopez et al., 2004; Cutullic et al., 2009). Twenty-two-day milk yield was the milk yield variable of choice for inclusion as it accounted for more variation than 305-d lactation milk yield. Number of cows in standing estrus was highly correlated with estrous behaviors, as $\mathrm{r}=0.67, \mathrm{r}=0.63, \mathrm{r}=0.52$, and $\mathrm{r}$ $=0.29$ were estimated for sum of mounts initiated, sum of mounts received, time spent in sexually active group, and secondary estrous signs initiated respectively; consequently, it was not added to the basic model because it described a similar measure representing the same information.

Because of the limited number of cows from each breed, sire effects were not included in the model and cows were assumed unrelated. The mean sum and mean counts per hour of behavioral signs, the mean number, mean duration, and mean percentage of the period expressing sexually active group behavior were calculated for periods of the estrous cycle defined previously.

The sum of behavioral signs was calculated as the total number of each behavior during each period for cows expressing a minimum of 1 mount interaction or standing when mounted behavior for mount estrus or standing estrus periods, respectively. For estimation of sum of behavioral signs during prestand and poststand, all cows expressing standing estrus with a minimum of
1 mount interaction before and after standing estrus, respectively, were included.

The mean counts per hour were calculated as the total number of each behavior for cows with minimum 2 mount interactions or 2 standing when mounted behaviors during mount estrus or standing estrus respectively, divided by the total length of the period. This can be expressed as $\sum_{i} x_{i j} / \sum_{i} t_{i j}$, where $x_{i j}$ is the number of a specific behavior for the $i$ th cow in the $j$ th period, and $t_{i j}$ is the corresponding length of the $j$ th period (Sveberg et al., 2011). For estimation of frequencies of behavioral signs during prestand and poststand, all cows expressing both mount estrus and standing estrus and a minimum of 2 secondary estrous signs were included.

The mean proportion of time (\%) spent in a sexually active group during the specific time periods were calculated similarly, as the time spent in these groups during a period for cows with minimum 2 mount interactions or 2 standing when mounted behaviors during mount or standing estrus respectively, divided by the total length of the same period. This can be expressed by the same formula as above except that $x_{i j}$ represents time (in seconds) for the $i$ th cow in period $j$. The mean duration of sexually active groups was calculated from the group starting and ending during the respective periods.

\section{RESULTS}

Based on progesterone measurements, 16 of $20 \mathrm{HF}$ and 19 of $20 \mathrm{NRF}$ were characterized as cyclic; however, 1 cyclic HF cow was excluded because the duration of her estrous cycle was $25 \mathrm{~d}$ (and consequently observations for a full estrous cycle were incomplete). All cyclic cows expressed mount estrus, but $2 \mathrm{HF}$ and $2 \mathrm{NRF}$ did not express standing behavior during mount estrus. The 15 HF cows and 19 NRF cows in mount estrus had average 22 -d milk yields $( \pm \mathrm{SE}$ ) of $542.6 \pm 19.1$ and $525.9 \pm 17.3 \mathrm{~kg}(P=0.52)$ and mean BCS $( \pm \mathrm{SE})$ of $2.95 \pm 0.09$ and $3.32 \pm 0.08(P<0.01)$, respectively. No significant interactions between breed and lactation number were detected.

\section{Duration of Estrus}

Large differences in estrus lengths between the 2 breeds were found in this study (Figure 1). Duration of estrus (mount estrus and standing estrus), mounting period, and mounted period were all significantly greater in NRF $(P<0.05)$ compared with HF (Table $1)$. The lengths of prestand and poststand, although 


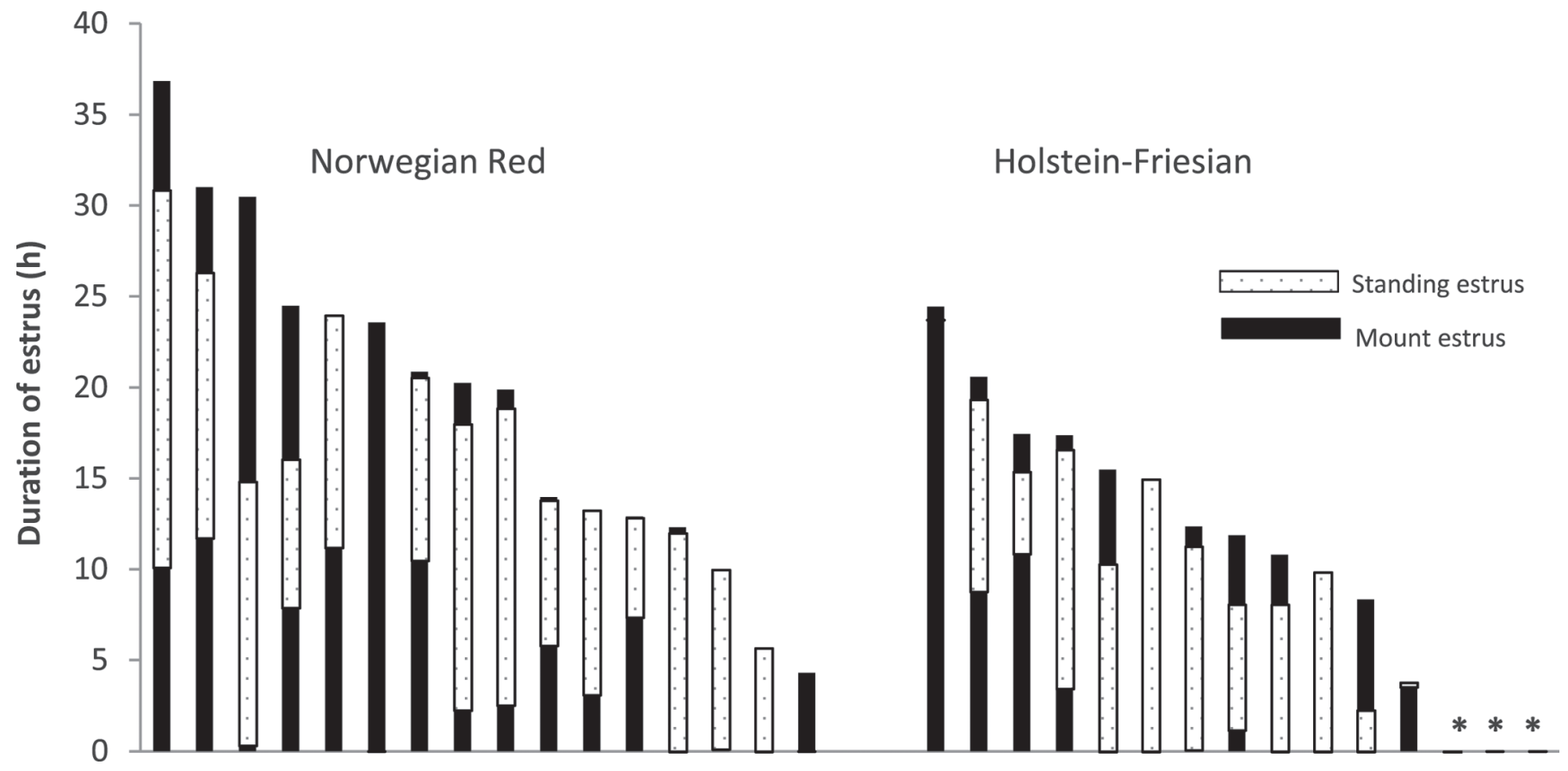

Figure 1. Duration (h) of individual estrus (mount and standing estrus) of 16 Norwegian Red and 15 Holstein-Friesian cows. Estrus duration for each cow is represented by a vertical bar describing the beginning of mount estrus starting at zero on the vertical axis. Mount estrus may start at the same time or be identical to standing estrus. ${ }^{*}$ Three HF cows with duration of mount estrus $<1 \mathrm{~h}$.

slightly greater in NRF compared with HF, were simi$\operatorname{lar}(P>0.10)$.

The durations of estrous periods were not significantly influenced $(P>0.05)$ by additional independent variables. However, milk yield had a tendency to affect mounting period $(P=0.06)$, mounted period $(P=$ $0.08)$, and standing estrus period $(P=0.10)$ durations. Breed still had a significant effect $(P<0.05)$ on the length of these periods after adding milk yield to the basic model.

\section{Sexually Active Groups}

The 2 breeds expressed similar patterns of time spent in sexually active groups through stages of estrous cycle (Table 2), but NRF spent significantly more time

Table 1. Duration (h) of estrus periods

\begin{tabular}{lrrrrrr}
\hline & \multicolumn{2}{c}{ No. of cows $^{2}$} & & \multicolumn{2}{c}{ LSM $^{3} \pm \mathrm{SE}$} & \\
\cline { 2 - 3 } \cline { 5 - 6 } Period $^{1}$ & HF & NRF & & HF & NRF & $P_{\text {-value }}^{4}$ \\
\hline Mount estrus & 15 & 19 & & $11.2 \pm 3.0$ & $21.3 \pm 2.7$ & 0.02 \\
Standing estrus & $13^{5}$ & $14^{5}$ & & $7.1 \pm 1.4$ & $11.7 \pm 1.3$ & 0.02 \\
Mounting period & 15 & 19 & & $6.9 \pm 2.7$ & $18.2 \pm 2.4$ & $<0.01$ \\
Mounted period & 15 & 18 & & $9.2 \pm 2.8$ & $17.5 \pm 2.6$ & 0.04 \\
Prestand & $13^{5}$ & $14^{5}$ & & $4.0 \pm 1.6$ & $5.1 \pm 1.6$ & 0.65 \\
Poststand & 13 & $14^{5}$ & & $1.8 \pm 1.0$ & $2.8 \pm 1.0$ & 0.52 \\
\hline
\end{tabular}

\footnotetext{
${ }^{1}$ Mount estrus $=$ the period from the first to the last mount interaction; standing estrus $=$ period from the first to the last standing when mounted event; mounting period $=$ the period from the first to the last mounting event; mounted period $=$ the period from the first to the last mounted event; prestand $=$ period from start of mount estrus until start of standing estrus; poststand = period from end of standing estrus until end of mount estrus.

${ }^{2} \mathrm{HF}=$ Holstein-Friesian cattle; NRF $=$ Norwegian Red cattle.

${ }^{3} \mathrm{LSM}=$ least squares means from generalized linear model (SAS Institute Inc., Cary, NC) with independent variables breed and lactation number.

${ }^{4} P$-value for the test of difference between breeds.

${ }^{5}$ Standing durations were not observed for $2 \mathrm{HF}$ and $2 \mathrm{NRF}$ during mount estrus and were incomplete for 3 $\mathrm{NRF}$ due to an electrical disruption for a 7 -h period. Consequently, duration of standing estrus, prestand, and poststand could not be determined for these 7 cows.
} 
in sexually active groups compared with HF during standing estrus and poststand, respectively (Figure 2; Appendix Table A1). For both breeds, sexually active groups were absent during nonestrus and proestrus (the last $24 \mathrm{~h}$ before estrus) until the last $3 \mathrm{~h}$ before mount estrus. Major differences were observed for both breeds in time spent in sexually active groups between mount estrus compared with nonestrus (Table 2). For $\mathrm{NRF}$, significant differences were observed between all consecutive periods from 1 to $3 \mathrm{~h}$ before mount estrus until 4 to $6 \mathrm{~h}$ after mount estrus. For HF, a significant difference was observed only between standing estrus and poststand period and a tendency to difference was observed between the poststand period and 1 to $3 \mathrm{~h}$ after mount estrus.

The HF breed participated in fewer sexually active groups $(5.9 \pm 1.4$ vs. $10.5 \pm 1.4 ; P=0.03)$ with a shorter average duration compared with NRF $(0.21 \pm$ 0.04 h vs. $0.38 \pm 0.04 \mathrm{~h} ; P=0.01$ ) in mount estrus. The $\mathrm{HF}$ participated in fewer sexually active groups during standing estrus $(5.5 \pm 1.3$ vs. $9.6 \pm 1.3 ; P=0.03)$ with a shorter average duration compared with NRF (0.20 $\pm 0.04 \mathrm{~h}$ vs. $0.42 \pm 0.04 \mathrm{~h} ; P<0.01)$. Luteal cows participating in sexually active groups were all partners of cows in, or $1 \mathrm{~h}$ before, mount estrus. Milk yield and BCS did not affect time spent in sexually active groups during estrus.

\section{Behavior During Estrus}

Initiated and received behaviors of $\mathrm{HF}$ and $\mathrm{NRF}$ cows during mount estrus are presented in Table 3. Similar breed differences were observed for estrous behaviors during standing estrus; consequently, detailed behav- iors during standing estrus and prestand and poststand periods are included in Tables A2, A3, and A4 in the Appendix.

The NRF breed initiated a greater number of total mounts that resulted more often in a standing response in the receiver cow compared with HF (Table 3). We also detected a tendency of more mounts initiated per hour and received mounts resulting more often in a standing response in NRF compared with HF cows (Table 3 ). The mean duration of single mounts was 4.00 \pm 0.36 vs. $5.1 \pm 2.2 \mathrm{~s}(P<0.01)$ for $\mathrm{HF}$ versus NRF during mount estrus. During prestand and poststand periods, no breed differences were observed in mounts initiated or received.

Standing still when mounted contributed to 50.0 and $53.1 \%$ of all mounts received for $\mathrm{HF}$ and NRF, respectively. Some of these standing events occurred when mounted sideways (2.0 and $1.5 \%$ ) or headways (5.8 and $9.0 \%$ ) in $\mathrm{HF}$ and $\mathrm{NRF}$, respectively.

The HF cows initiated more anogenital sniff and chaseup behaviors per hour during mount estrus, and NRF participated in more head butt interactions (Table 3). No breed differences were observed when summarizing the 4 traditional secondary estrous behaviors (mount, attempt to mount, anogenital sniff, and chin rest) or after adding 3 additional estrous behaviors (chase-up, head butt, and play rub; Table 3) to the 4 traditional behaviors. For other social agonistic behaviors, HF received more push aways per hour $(1.0 \pm 0.2$ vs. $0.3 \pm$ $0.2 ; P=0.05)$, whereas NRF tended to initiate more body butts per hour $(1.7 \pm 0.6$ vs. $0.2 \pm 0.6 ; P=0.07)$ during standing estrus.

Around standing estrus, a difference was observed only for $\mathrm{HF}$ initiating total more chase-up behaviors

Table 2. Comparison of sexually active group (SAG 3-5) fraction ${ }^{1}(\%)$ between periods of estrous cycle within breed

\begin{tabular}{|c|c|c|c|c|c|c|c|}
\hline Period $1^{2}$ & Period 2 & \multicolumn{3}{|c|}{$\mathrm{NRF}^{3}\left(\mathrm{LSM}^{4} \pm \mathrm{SE}\right)$} & \multicolumn{3}{|c|}{$\mathrm{HF}^{5}(\mathrm{LSM} \pm \mathrm{SE})$} \\
\hline Nonestrus & Mount estrus (MTE) & $0 \pm 2.5$ & $24.2 \pm 2.7$ & $<0.01$ & $0.1 \pm 3.0$ & $16.5 \pm 3.4$ & $<0.01$ \\
\hline 1-3 h before MTE & Prestand & $0.8 \pm 3.2$ & $16.1 \pm 4.1$ & $<0.01$ & $2.0 \pm 3.6$ & $13.2 \pm 5.8$ & 0.12 \\
\hline Prestand & Standing estrus & $15.0 \pm 5.9$ & $36.3 \pm 5.4$ & 0.01 & $13.2 \pm 8.2$ & $22.2 \pm 6.0$ & 0.39 \\
\hline Standing estrus & Poststand & $35.9 \pm 4.5$ & $17.7 \pm 5.6$ & 0.02 & $21.3 \pm 3.8$ & $1.3 \pm 4.2$ & $<0.01$ \\
\hline \multicolumn{8}{|c|}{$\begin{array}{l}\text { IFraction }=\text { percentage time spent in SAG } 3-5 \text { out of total time spent in period; SAG } 3-5=\text { event defined by cow participating in a minimum } \\
\text { of } 1 \text { estrous behavior per } 5 \text { min with its sexually active partner }(\mathrm{s}) \text { while staving within } 3 \mathrm{~m}(2 \text { cow lengths }) \text {. }\end{array}$} \\
\hline \multicolumn{8}{|c|}{$\begin{array}{l}{ }^{2} \text { Nonestrus = selected day with no cows in estrus; prestand = period from start of mount estrus until start of standing estrus; poststand }=\text { perioc } \\
\text { from end of standing estrus until end of mount estrus. }\end{array}$} \\
\hline \multicolumn{8}{|c|}{${ }^{3} \mathrm{NRF}=$ Norwegian Red cattle. } \\
\hline \multicolumn{8}{|c|}{$\begin{array}{l}{ }^{4} \mathrm{LSM} \text { for percent of period spent in SAG 3-5 from generalized linear model (SAS Institute Inc., Cary, NC) with independent variables perioc } \\
\text { and lactation number. }\end{array}$} \\
\hline
\end{tabular}




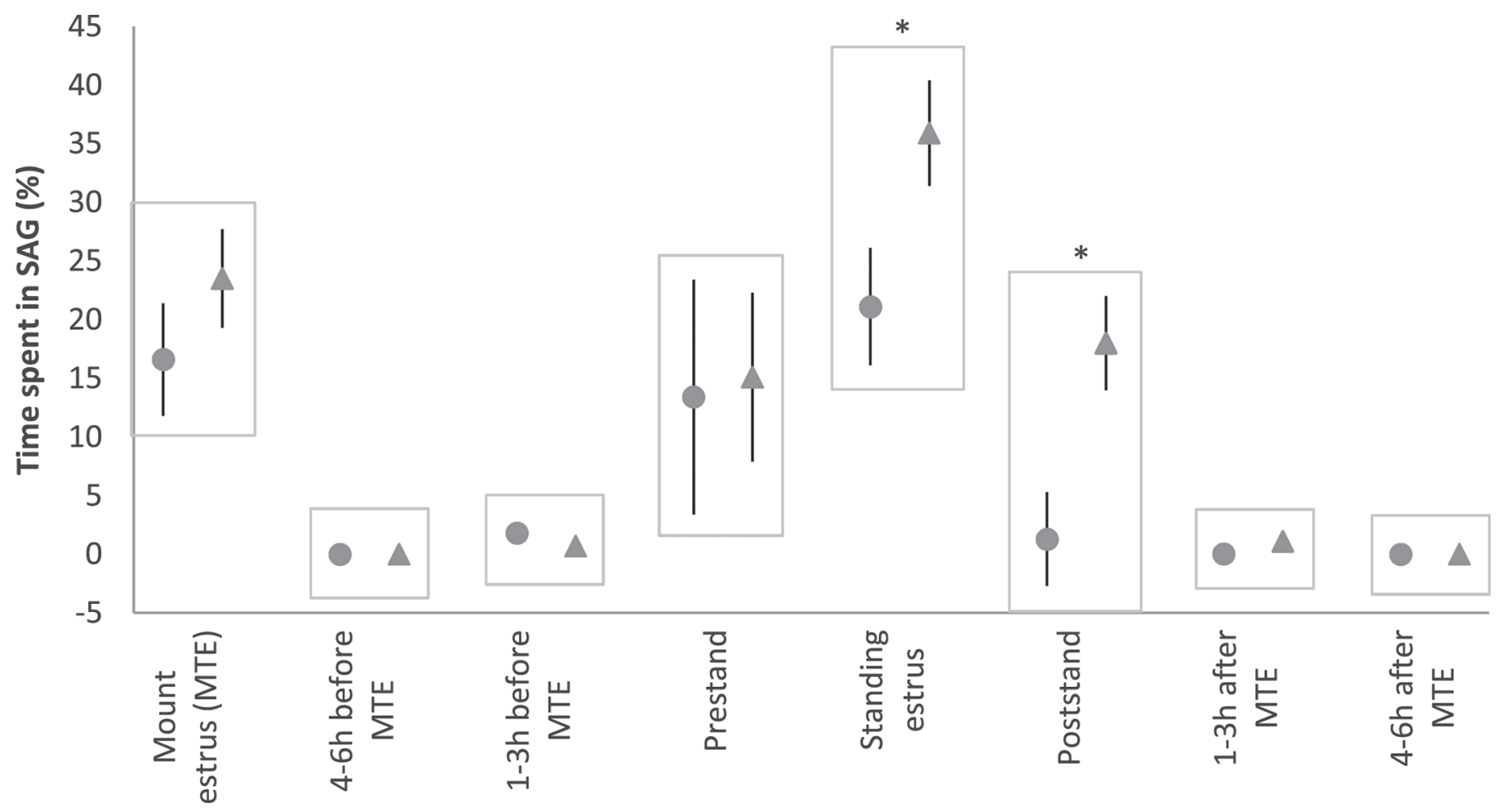

Figure 2. Percentage of time spent in sexually active group (SAG), with standard errors, out of total time spent in specific periods of estrous cycle presented as least squares means from generalized linear model (SAS Institute Inc., Cary, NC) with independent variables breed (HolsteinFriesian $=\bullet$ and Norwegian Red $=\boldsymbol{\Delta}$ ) and lactation number. SAG 3-5= cow participating in a minimum of 1 estrous behavior per 5 min with its sexually active partner(s) while staying within $3 \mathrm{~m} \mathrm{(2} \mathrm{cow} \mathrm{lengths);} \mathrm{mount} \mathrm{estrus} \mathrm{=} \mathrm{the} \mathrm{period} \mathrm{from} \mathrm{the} \mathrm{first} \mathrm{to} \mathrm{the} \mathrm{last} \mathrm{mount} \mathrm{interaction;}$ prestand $=$ hour interval before standing estrus from start of mount estrus; standing estrus = period from the first to the last standing when mounted event; poststand $=$ hour interval after standing estrus until end of mount estrus. ${ }^{*} P$-value $<0.05$ for the test of difference between breeds for time spent in SAG 3-5 during period.

during prestand $(P=0.04)$ and NRF initiating more mounts per hour resulting in a standing response during poststand period $(P=0.03$; Appendix Tables A3 and A4). Holstein-Friesian cows tended $(P=0.06)$ to initiate more total anogenital sniffs during prestand, whereas NRF cows tended to initiate more mounts $(P$ $=0.09)$ and chin rests $(P=0.06)$ per hour, receive more anogenital sniffs per hour $(P=0.09)$, and interact more in head butts during poststand $(P=0.08)$.

Received signs were significantly affected by the independent variable BCS, both the sum of 7 signs and single secondary estrous signs except chase-up. The observed breed difference for head butt behavior changed from $P=0.01$ to $P=0.20$ after including BCS in the model such that no breed differences were found for received secondary estrous signs after including the effect of BCS. In this expanded model, multiparous cows tended to receive more secondary estrous signs (sum of 7 received signs) compared with primiparous cows $(146.8 \pm 22.5$ vs. $82.3 \pm 24.6 ; P=0.07)$, regardless of breed. Milk yield affected only attempted mounts, so that HF initiated significantly more unsuccessful mounts per hour compared with NRF (1.6 \pm 0.3 vs.
$0.6 \pm 0.3 ; P=0.04)$ in an expanded model including milk yield.

\section{DISCUSSION}

\section{Duration of Estrus}

The present study reported breed differences in favor of NRF for durations of mount estrus, standing estrus, and mounting and mounted periods (Table 1), despite large individual differences within breeds (Figure 1), similar milk yield, favorable outdoor environment, and the small number of cows included in the study. Our results are supported by evidence in the literature of a decline in standing estrus length from 15 to $5 \mathrm{~h}$ and fewer mounting and standing behaviors expressed by the HF breed (Pennington et al., 1986; Dobson et al., 2008). The NRF breed, on the other hand, has maintained high reproductive performance in the same period with selection programs that prioritize fertility and health traits (Philipsson and Lindhé, 2003; Refsdal, 2007). The use of breeds or individual cows with longer estrus duration or stronger estrous expression might improve 
Table 3. Behaviors during mount estrus for 15 Holstein-Friesian (HF) and 16 Norwegian Red (NRF) cows

\begin{tabular}{|c|c|c|c|c|c|c|}
\hline \multirow[b]{2}{*}{ Behavior } & \multicolumn{2}{|c|}{$\begin{array}{l}\text { Total number } \\
\left(\mathrm{LSM}^{1} \pm \mathrm{SE}\right)\end{array}$} & \multirow[b]{2}{*}{$P$-value ${ }^{3}$} & \multicolumn{2}{|c|}{$\begin{array}{l}\text { Counts per hour }{ }^{2} \\
\quad(\mathrm{LSM} \pm \mathrm{SE})\end{array}$} & \multirow[b]{2}{*}{$P$-value } \\
\hline & $\mathrm{HF}$ & NRF & & $\mathrm{HF}$ & $\mathrm{NRF}$ & \\
\hline Mount initiated & $18.1 \pm 6.3$ & $46.3 \pm 6.2$ & $<0.01$ & $1.5 \pm 0.5$ & $2.6 \pm 0.4$ & 0.08 \\
\hline Mount initiated with standing response & $7.5 \pm 4.4$ & $24.1 \pm 4.3$ & 0.01 & $0.6 \pm 0.3$ & $1.4 \pm 0.3$ & 0.10 \\
\hline Attempt to mount initiated & $13.3 \pm 3.4$ & $12.4 \pm 3.3$ & 0.85 & $1.5 \pm 0.3$ & $0.7 \pm 0.3$ & 0.11 \\
\hline Head butt mutual $^{4}$ & $14.2 \pm 4.8$ & $32.3 \pm 4.7$ & 0.01 & $1.4 \pm 0.3$ & $1.7 \pm 0.3$ & 0.46 \\
\hline Play rub mutual & $7.3 \pm 4.7$ & $16.6 \pm 4.6$ & 0.17 & $0.7 \pm 0.2$ & $0.8 \pm 0.2$ & 0.82 \\
\hline Primary estrous sign: standing when mounted & $15.9 \pm 5.1$ & $28.5 \pm 5.0$ & 0.09 & $1.6 \pm 0.4$ & $1.5 \pm 0.3$ & 0.94 \\
\hline Sum of the following 7 secondary estrous signs & $84.9 \pm 30.5$ & $144.5 \pm 30.0$ & 0.18 & $7.7 \pm 1.5$ & $7.1 \pm 1.3$ & 0.77 \\
\hline Mount received & $12.9 \pm 6.1$ & $24.1 \pm 6.0$ & 0.20 & $1.1 \pm 0.3$ & $1.1 \pm 0.3$ & 0.93 \\
\hline Attempt to mount received & $5.3 \pm 3.2$ & $8.3 \pm 3.1$ & 0.51 & $0.4 \pm 0.2$ & $0.4 \pm 0.1$ & 0.89 \\
\hline
\end{tabular}

heat detection rates and simplify the daily tasks of the farmers using mount detectors or visual observations in estrus detection programs. Genetic variation in estrous expression (Løvendahl and Chagunda, 2009) may explain our results and some of the previously reported differences in fertility between the 2 breeds (Walsh et al., 2008), but further research is necessary to further substantiate this.

Mount estrus was observed in all cyclic $(80 \% \mathrm{HF}$ and $95 \% \mathrm{NRF}$ ) cows as the continuous data collection detected HF cows with very short mount and standing estrus durations (Figure 1), similar to the results of Lopez et al. (2004). Because of the documented decline in standing when mounted behavior, a stronger emphasis on the mount estrus period would be beneficial both for research and management purposes.

No differences in duration were observed for prestand and poststand periods. The small number of cows (Table 1) could have affected our ability to detect breed differences for these specific periods within estrus. To our knowledge, no recent studies since the detailed study of Hurnik et al. (1975) have reported duration of prestand and poststand periods. These periods and mounting and mounted behaviors represent proceptive and receptive patterns that characterize, and consequently enable the observer to detect specific periods in, mount estrus (Sveberg et al., 2013). This may be of major importance for successful timing of insemination
(Walker et al., 1996). Roelofs et al. (2005) identified the start of mount and stand periods as the events most strongly associated with time of ovulation. We suggest that similar investigations should be made with recording of the behavioral characteristics described in the present study.

Additional variables were nonsignificant for all periods in estrus when added to the basic model, in agreement with previous studies (Britt et al., 1986; Cutullic et al., 2009) but in contrast to the results of Hurnik et al. (1975) for the effect of number of cows in estrus. We still observed a significant effect of breed on mounting and mounted period when milk yield was added to the basic model.

\section{Sexually Active Groups}

The study revealed major differences in time spent in sexually active groups between the 2 breeds. Even though they expressed similar patterns of these groups throughout the estrous cycle, major differences between all consecutive periods during and around estrus were detected only for the NRF breed. The NRF cows participated in a greater number of sexually active groups with longer average duration and consequently they spent significant more time in sexually active groups during standing estrus and poststand. These 2 periods coincide with the optimal time to breed dairy cattle ac- 
cording to Roelofs et al. (2005), and a longer duration of sexual activity may favor heat detection in the NRF breed. Improved knowledge of sexually active group behavior may improve estrus detection success rates in different dairy breeds and increase the possibility of detecting estrous cows with weak expression of mount or standing behaviors (Sveberg et al., 2013).

The breed differences in time spent in sexually active groups could nevertheless be caused by differences in proximity behavior, as no difference in sum or frequencies of secondary estrous signs, the other prerequisite of sexually active groups, was observed between the 2 breeds (Table 3). Possible differences in proximity behaviors could be of interest to investigate in further studies. The current study included additional secondary estrous signs (Mülleder et al., 2003; Kerbrat and Disenhaus, 2004; Sveberg et al., 2013), not only the primary estrous sign reported in previous studies of sexually active groups (Law et al., 2009), thus avoiding possible breed differences in sexually active group frequency or estrous behaviors related to infrequent mounting and standing behaviors previously reported in the HF breed (Dobson et al., 2008).

\section{Behavior During Estrus}

The intense data collection through complete estrous cycles resulted in accurate data for the observed behaviors. Norwegian Red cattle expressed more primary estrous signs (standing when mounted) and initiated more mounts compared with HF, despite a considerably greater number of standing and mounting events for $\mathrm{HF}$ reported in this study compared with other continuous studies (Rodtian et al., 1996; Kerbrat and Disenhaus, 2004). This may be due to effect of spontaneous estruses (Walton et al., 1987), soft flooring (Phillips and Schofield, 1990), and moderate milk yield (Lopez et al., 2004) in the current study. The NRF breeding system, incorporating fertility traits as an important part of the selection process for the last $40 \mathrm{yr}$, may explain the observed difference (Philipsson and Lindhé, 2003; Chang et al., 2006; Refsdal, 2007). A study by Walsh et al. (2008) documented breed differences in reproductive performance despite similar milk and milk solids production in the 2 breeds. The observed number of HF cows with 1 stand or 1 mount event during estrus was in agreement with the results of a study that included a larger number of cows (Lopez et al., 2004). The NRF breed maintained significantly higher frequencies of mounting behavior through standing estrus and late stages of estrus (poststand), which could make it easier for the farmer to detect this important behavior during stages of estrus that are regarded as being the optimal time window to breed cows (Nebel et al., 2000).
For other secondary estrous signs, HF cows expressed more anogenital sniffing and chase-up behaviors per hour, whereas the NRF breed participated more often in head butts. By including additional estrous behaviors (head butt, chase-up, and play rub) in an extended definition of secondary estrous signs (Sveberg et al., 2011, 2013), breed differences in other behavioral traits were detected. However, no breed differences were observed when summarizing all secondary estrous signs.

When including additional independent variables, a considerable effect of number of cows in standing estrus was observed on mounts per hour, in agreement with previous studies (Roelofs et al., 2005; Sveberg et al., 2011). Body condition score (Buckley et al., 2003; Cutullic et al., 2012) is reported to influence reproductive performance, which may explain the significant effect of BCS on received secondary estrous signs observed in the current study. The HF had slightly lower BCS compared with NRF, and secondary estrous signs received increased in $\mathrm{HF}$ when adding $\mathrm{BCS}$ to the model, although no breed differences were detected. A study by Gillund et al. (1999) recommend a modified BCS scoring system for the NRF breed because the breed has less subcutaneous fat compared with HF. The BCS method of Lowman et al. (1976) was used for both breeds in the current study, which may explain some of the observed breed differences in BCS.

\section{CONCLUSIONS}

The current study provides new information on effects of breed and additional variables on estrous expression in dairy cows. Longer estrus periods with more of the primary sign standing when mounted, mount and head butt behaviors, and more time spent in sexually active groups were observed in NRF compared with the HF breed. The HF cows, on the other hand, initiated more of the secondary signs anogenital sniffing and chase-up per hour. This study indicates that choice of breed affects behavioral characteristics and duration of estrus, which may consequently influence heat detection rates in dairy farms.

\section{ACKNOWLEDGMENTS}

The authors thank N. Byrne and the Ballydague farm staff for care of animals and help with this study. We also thank J. Rudi at Timotei Data (Ringebu, Norway) for video recording, Ellen Dahl (Norwegian University of Life Science, Ås, Norway) for laboratory assistance, and Jörund Hage (National Institute of Nutrition and Seafood Research, Oslo, Norway) for help with data handling. Support for the preparation of the anti-progesterone monoclonal antibody and the 
progesterone peroxidase conjugate was provided by the Estonian Science Foundation (Tallinn, Estonia). The study was funded by the Norwegian Research Council projects "Oestrus and Oestrus Behaviour in NRF and Holstein Breeds in Modern Cattle Housing Systems" (Oslo, Norway; 173974/I10).

\section{REFERENCES}

Boichard, D., and M. Brochard. 2012. New phenotypes for new breeding goals in dairy cattle. Animal 6:544-550.

Britt, J. H., R. G. Scott, J. D. Armstrong, and M. D. Whitacre. 1986. Determinants of estrous behavior in lactating Holstein cows. J. Dairy Sci. 69:2195-2202.

Buckley, F., J. Mee, K. O`Sullivan, R. Evans, D. Berry, and P. Dillon. 2003. Insemination factors affecting the conception rate in seasonal calving Holstein-Friesian cows. Reprod. Nutr. Dev. 43:543-555.

Chang, Y. M., I. M. Andersen-Ranberg, B. Heringstad, D. Gianola, and G. Klemetsdal. 2006. Bivariate analysis of number of services to conception and days open in Norwegian Red using a censored threshold-linear model. J. Dairy Sci. 89:772-778.

Cutullic, E., L. Delaby, D. Causeur, G. Michel, and C. Disenhaus. 2009. Hierarchy of factors affecting behavioural signs used for oestrus detection of Holstein and Normande dairy cows in a seasonal calving system. Anim. Reprod. Sci. 113:22-37.

Cutullic, E., L. Delaby, Y. Gallard, and C. Disenhaus. 2012. Towards a better understanding of the respective effects of milk yield and body condition dynamics on reproduction in Holstein dairy cows. Animal 6:476-487.

Dobson, H., S. L. Walker, M. J. Morris, J. E. Routly, and R. F. Smith. 2008. Why is it getting more difficult to successfully artificially inseminate dairy cows? Animal 2:1104-1111.

Gillund, P., O. Reksen, K. Karlberg, Å. T. Randby, I. Engeland, and B. Lutnæs. 1999. Utpröving av en holdvurderingsmetode paa NRF-kyr (Testing of a body condition score method in Norwegian cattle). Nor. Vet. Tidsskr. 111:623-632.

Hammond, J. 1927. The Physiology of Reproduction in the Cow. Cambridge University Press, Cambridge, UK.

Hurnik, J. F., G. J. King, and H. A. Robertson. 1975. Estrous and related behavior in postpartum Holstein cows. Appl. Anim. Ethol. 2:55-68.

Jensen, P., B. Buitenhuis, J. Kjaer, A. Zanella, P. Mormède, and T. Pizzari. 2008. Genetics and genomics of animal behaviour and welfare-Challenges and possibilities. Appl. Anim. Behav. Sci. 113:383-403.

Kerbrat, S., and C. Disenhaus. 2004. A proposition for an updated behavioral characterization of the oestrus period in dairy cows. Appl. Anim. Behav. Sci. 87:223-238.

Landaeta-Hernández, A. J., R. Palomares-Naveda, G. Soto-Castillo, A. Atencio, C. C. Chase Jr., and P. J. Chenoweth. 2004. Social and breed effects on the expression of a PGF2 $\alpha$ induced oestrus in beef cows. Reprod. Domest. Anim. 39:315-320.

Law, R. A., F. J. Young, D. C. Patterson, D. J. Kilpatrick, A. R. G. Wylie, and C. S. Mayne. 2009. Effect of dietary protein content on estrous behavior of dairy cows during early and mid lactation. J. Dairy Sci. 92:1013-1022.

Lopez, H., L. D. Satter, and M. C. Wiltbank. 2004. Relationship between level of milk production and estrous behavior of lactating dairy cows. Anim. Reprod. Sci. 81:209-223.

Løvendahl, P., and M. G. G. Chagunda. 2009. Genetic variation in estrus activity traits. J. Dairy Sci. 92:4683-4688.

Løvendahl, P., M. G. G. Chagunda, J. O'Connell, and N. Friggens. 2009. Genetics of fertility indicators based on behaviour and progesterone in milk. Cattle Pract. 17:7-12.

Lowman, B. G., N. A. Scott, and S. H. Somerville. 1976. Condition Scoring of Cattle. Rev. ed. Bulletin no. 6. East of Scotland College of Agriculture, Edinburgh, UK.
Mülleder, C., P. Palme, C. Menke, and S. Waiblinger. 2003. Individual differences in behavior and in adrenocortical activity in beef-suckler cows. Appl. Anim. Behav. Sci. 84:167-183.

Nebel, R. L., M. G. Dransfield, S. M. Jobst, and J. H. Bame. 2000. Automated electronic systems for the detection of oestrus and timing of AI in cattle. Anim. Reprod. Sci. 60-61:713-723.

Pennington, J. A., J. L. Albright, and C. J. Callahan. 1986. Relationships of sexual activities in estrous cows to different frequencies of observation and pedometer measurements. J. Dairy Sci. 69:2925-2934.

Philipsson, J., and B. Lindhé. 2003. Experiences of including reproduction and health traits in Scandinavian dairy cattle breeding programmes. Livest. Prod. Sci. 83:99-112.

Phillips, C. J. C., and S. A. Schofield. 1990. The effect of environment and stage of the oestrous cycle on the behaviour of dairy cows. Appl. Anim. Behav. Sci. 27:21-31.

Rae, D. O., P. J. Chenoweth, M. A. Giangreco, P. W. Dixon, and F. L. Bennett. 1999. Assessment of estrus detection by visual observation and electronic detection methods and characterization of factors associated with estrus and pregnancy in beef heifers. Theriogenology 51:1121-1132.

Refsdal, A. O. R. 2007. Reproductive performance of Norwegian cattle from 1985 to 2005: trends and seasonality. Acta Vet. Scand. 49:5-11.

Rodtian, P., G. King, S. Subrod, and P. Pongpiachan. 1996. Oestrous behaviour of Holstein cows during cooler and hotter tropical seasons. Anim. Reprod. Sci. 45:47-58.

Roelofs, J. B., F. J. van Eerdenburg, N. M. Soede, and B. Kemp. 2005. Various behavioral signs of estrous and their relationship with time of ovulation in dairy cattle. Theriogenology 63:1366-1377.

Senger, P. L. 1994. The estrus detection problem: New concepts, technologies, and possibilities. J. Dairy Sci. 77:2745-2753.

Sprecher, D. J., D. E. Hostetler, and J. B. Kaneene. 1997. A lameness scoring system that uses posture and gait to predict dairy cattle reproductive performance. Theriogenology 47:1179-1187.

Sveberg, G., A. O. Refsdal, H. W. Erhard, E. Kommisrud, M. Aldrin, I. F. Tvete, F. Buckley, A. Waldmann, and E. Ropstad. 2011. Behavior of lactating Holstein-Friesian cows during spontaneous cycles of estrus. J. Dairy Sci. 94:1289-1301.

Sveberg, G., A. O. Refsdal, H. W. Erhard, E. Kommisrud, M. Aldrin, I. F. Tvete, F. Buckley, A. Waldmann, and E. Ropstad. 2013. Sexually active groups in cattle-A novel estrus sign. J. Dairy Sci. 96:4375-4386.

Trimberger, W. T. 1948. Breeding efficiency in dairy cattle from artificial insemination at various intervals before and after ovulation. Univ. Nebraska Agric. Exp. Sta. Res. Bull. 153:3-25.

Van Vliet, J. H., and F. J. C. M. van Eerdenburg. 1996. Sexual activities and oestrus detection in lactating Holstein cows. Appl. Anim. Behav. Sci. 50:57-69.

Waldmann, A. 1993. Enzyme immunoassay (EIA) for milk progesterone using a monoclonal antibody. Anim. Reprod. Sci. 34:19-30.

Waldmann, A. 1999. Monoclonal antibodies to progesterone: Characterization and selection for enzyme immunoassay in bovine milk. Hybridoma 18:289-296.

Walker, W. L., R. L. Nebel, and M. L. McGilliard. 1996. Time of ovulation relative to mounting activity in dairy cattle. J. Dairy Sci. 79:1555-1561.

Walsh, S., F. Buckley, K. Pierce, N. Byrne, J. Patton, and P. Dillon. 2008. Effects of breed and feeding system on milk production, body weight, body condition score, reproductive performance, and postpartum ovarian function. J. Dairy Sci. 91:4401-4413.

Walton, J. S., L. P. Veenhuizen, and G. J. King. 1987. Relationships between time of day, estrous behavior, and the preovulatory luteinizing hormone surge in Holstein cows after treatment with cloprostenol. J. Dairy Sci. 70:1652-1663. 


\section{APPENDIX}

Table A1. Comparison of percentage of time spent in sexually active group (SAG $3-5^{1}$ ) by breed for periods of estrous cycle

\begin{tabular}{|c|c|c|c|c|c|}
\hline \multirow[b]{2}{*}{ Period $^{2}$} & \multicolumn{2}{|c|}{ No. of cows ${ }^{3}$} & \multicolumn{2}{|c|}{$\mathrm{LSM}^{4} \pm \mathrm{SE}$} & \multirow[b]{2}{*}{$P$-value ${ }^{5}$} \\
\hline & $\mathrm{HF}$ & $\mathrm{NRF}$ & $\mathrm{HF}$ & $\mathrm{NRF}$ & \\
\hline Nonestrus & 15 & 16 & 0 & 0 & - \\
\hline 4-6 h before mount estrus & 15 & 16 & 0 & 0 & - \\
\hline $1-3 \mathrm{~h}$ before mount estrus & 15 & 16 & $1.8 \pm 0.9$ & $0.7 \pm 0.8$ & 0.35 \\
\hline Mount estrus & 12 & 16 & $16.6 \pm 4.8$ & $23.5 \pm 4.2$ & 0.29 \\
\hline Prestand & 6 & 12 & $13.4 \pm 10.0$ & $15.1 \pm 7.2$ & 0.89 \\
\hline Standing estrus & 11 & 14 & $21.1 \pm 5.0$ & $35.9 \pm 4.5$ & 0.04 \\
\hline Poststand & 9 & 9 & $1.3 \pm 4.0$ & $18.0 \pm 4.0$ & 0.01 \\
\hline $1-3 \mathrm{~h}$ after mount estrus & 15 & 16 & $0.03 \pm 0.4$ & $1.1 \pm 0.4$ & 0.05 \\
\hline $4-6 \mathrm{~h}$ after mount estrus & 15 & 16 & 0 & 0 & - \\
\hline
\end{tabular}

${ }^{1}$ SAG $3-5=$ cow participating in a minimum of 1 estrous behavior per 5 min with its sexually active partner(s) while staying within $3 \mathrm{~m}$.

${ }^{2}$ Nonestrus $=$ selected day with no cows in estrus; prestand $=$ period from start of mount estrus until start of standing estrus; poststand $=$ period from end of standing estrus until end of mount estrus.

${ }^{3} \mathrm{HF}=$ Holstein-Friesian cattle; NRF $=$ Norwegian Red cattle.

${ }^{4} \mathrm{LSM}=$ least squares means of percentage of period spent in SAG 3-5 from generalized linear model (SAS Institute Inc., Cary, NC) with independent variables breed and lactation number.

${ }^{5} P$-value for the test of breed effect.

Table A2. Behaviors during standing estrus for 13 Holstein-Friesian (HF) and 14 Norwegian Red (NRF) cows

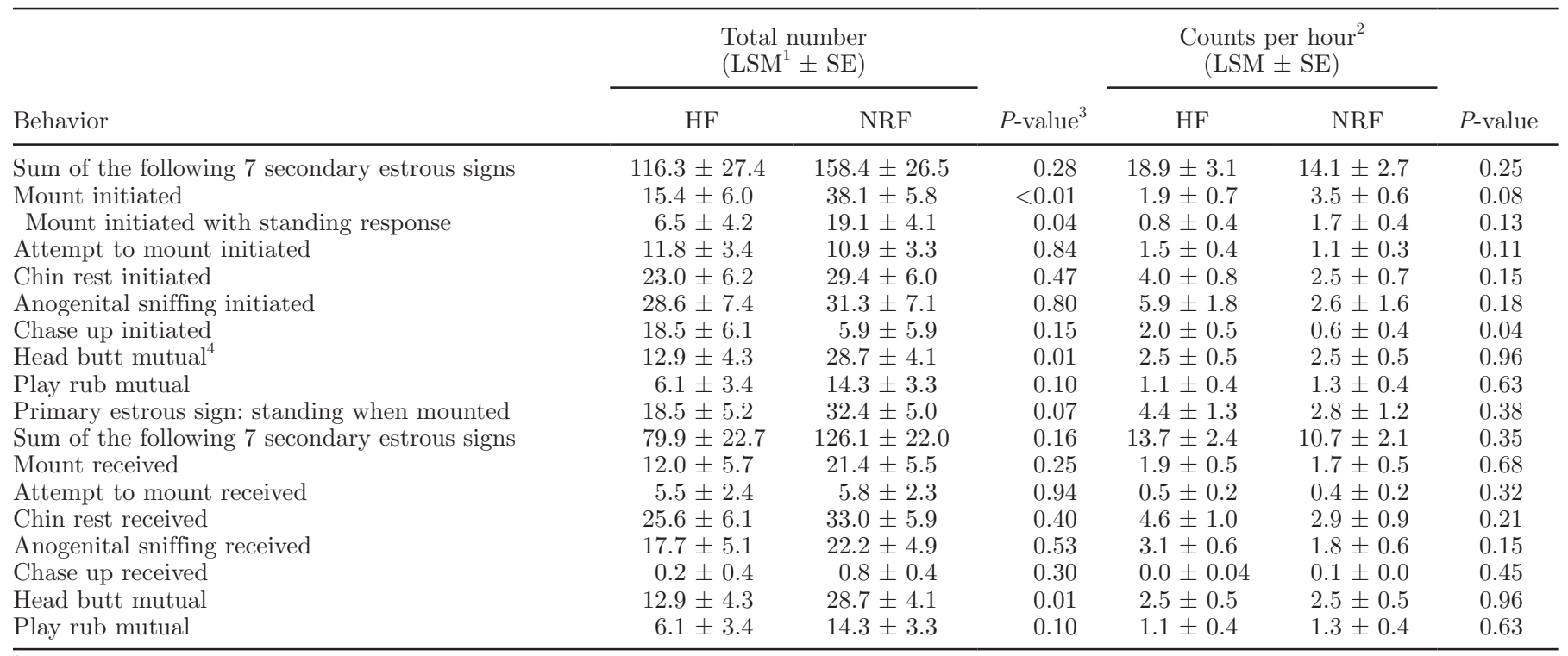

${ }^{1}$ LSM from generalized linear model (SAS Institute Inc., Cary, NC) with independent variables breed and lactation number.

${ }^{2}$ Two Holstein cows were omitted when analyzing counts per hour because durations of standing estrus period $<0.002 \mathrm{~h}$ resulted in extreme outliers.

${ }^{3} P$-value for the test of difference between breeds.

${ }^{4}$ Mutual behaviors $=$ behaviors that were both initiated and received by the involved cows. 
Table A3. Behaviors during prestand period for 7 Holstein-Friesian (HF) and 12 Norwegian Red (NRF) cows

\begin{tabular}{|c|c|c|c|c|c|c|}
\hline \multirow[b]{2}{*}{ Behaviors } & \multicolumn{2}{|c|}{$\begin{array}{l}\text { Total number } \\
\left(\mathrm{LSM}^{1} \pm \mathrm{SE}\right)\end{array}$} & \multirow[b]{2}{*}{$P$-value ${ }^{3}$} & \multicolumn{2}{|c|}{$\begin{array}{l}\text { Counts per hour } \\
\quad(\mathrm{LSM} \pm \mathrm{SE})\end{array}$} & \multirow[b]{2}{*}{$P$-value } \\
\hline & $\mathrm{HF}$ & NRF & & $\mathrm{HF}$ & $\mathrm{NRF}$ & \\
\hline Mount initiated & $7.6 \pm 3.9$ & $7.3 \pm 3.1$ & 0.96 & $1.2 \pm 0.5$ & $1.4 \pm 0.3$ & 0.70 \\
\hline Mount initiated with standing response & $3.0 \pm 3.2$ & $4.8 \pm 2.5$ & 0.67 & $0.4 \pm 0.4$ & $0.7 \pm 0.3$ & 0.51 \\
\hline Attempt to mount initiated & $5.3 \pm 1.9$ & $1.9 \pm 1.5$ & 0.18 & $1.0 \pm 1.9$ & $1.7 \pm 1.3$ & 0.76 \\
\hline Chase up initiated & $2.7 \pm 0.8$ & $0.4 \pm 0.7$ & 0.04 & $0.4 \pm 0.9$ & $0.6 \pm 0.7$ & 0.81 \\
\hline Head butt mutual $^{4}$ & $4.3 \pm 1.8$ & $4.9 \pm 1.4$ & 0.78 & $1.1 \pm 1.1$ & $2.6 \pm 0.8$ & 0.29 \\
\hline Play rub mutual & $3.7 \pm 1.8$ & $1.6 \pm 1.4$ & 0.38 & $0.7 \pm 0.4$ & $0.5 \pm 0.3$ & 0.60 \\
\hline Sum of the following 7 secondary estrous signs & $22.7 \pm 9.4$ & $15.9 \pm 7.4$ & 0.57 & $3.5 \pm 3.4$ & $7.3 \pm 2.4$ & 0.37 \\
\hline Mount received & $2.5 \pm 1.9$ & $2.4 \pm 1.5$ & 0.96 & $0.2 \pm 0.9$ & $1.0 \pm 0.7$ & 0.45 \\
\hline Attempt to mount received & $0.8 \pm 0.9$ & $1.5 \pm 0.7$ & 0.52 & $0.2 \pm 0.3$ & $0.6 \pm 0.2$ & 0.36 \\
\hline Chin rest received & $5.3 \pm 2.0$ & $1.7 \pm 1.6$ & 0.17 & $0.8 \pm 1.1$ & $1.5 \pm 0.8$ & 0.56 \\
\hline
\end{tabular}

${ }^{1}$ LSM from generalized linear model (SAS Institute Inc., Cary, NC) with independent variables breed and lactation number.

${ }^{2}$ Three Holstein cows were omitted when analyzing counts per hour because durations of prestand period $<0.002 \mathrm{~h}$ resulted in extreme outliers. ${ }^{3} P$-value for the test of difference between breeds.

${ }^{4}$ Mutual behaviors $=$ behaviors that were both initiated and received by the involved cows.

Table A4. Behaviors during poststand period for 9 Holstein-Friesian (HF) and 10 Norwegian Red (NRF) cows

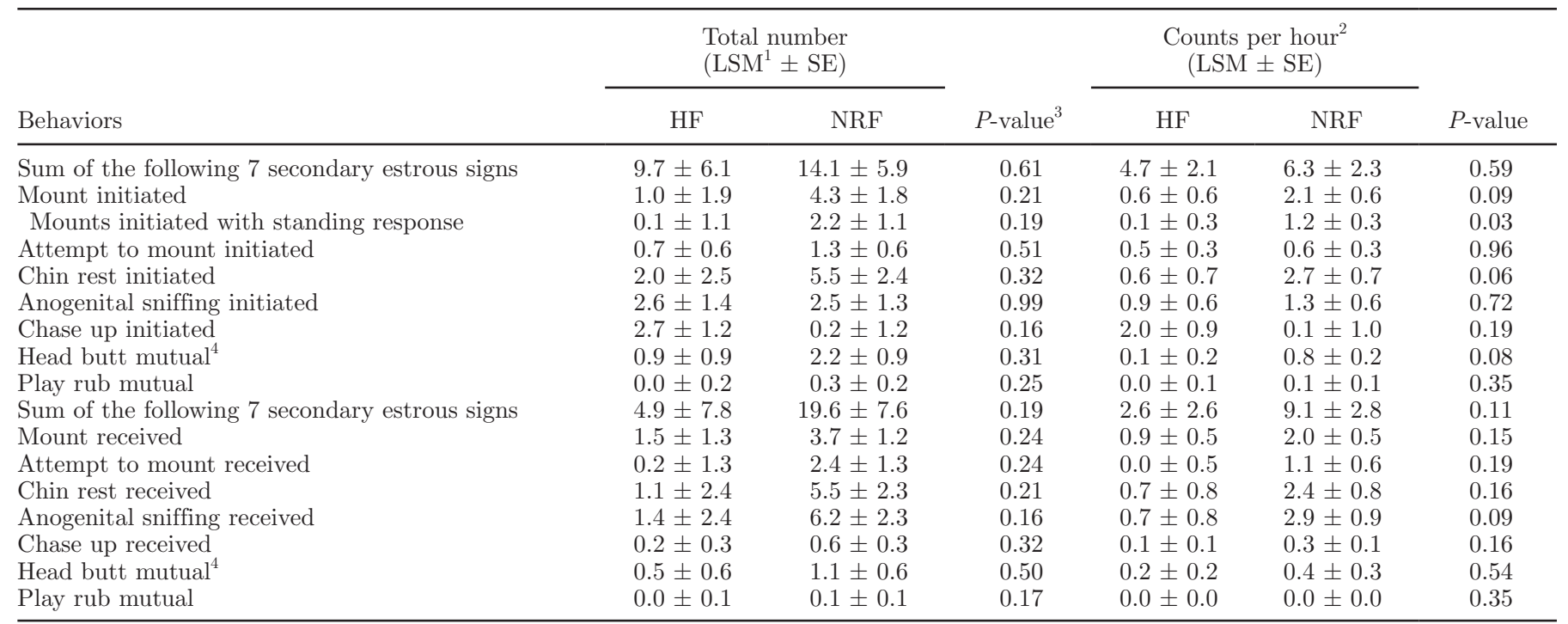

${ }^{1}$ LSM from generalized linear model (SAS Institute Inc., Cary, NC) with independent variables breed and lactation number.

${ }^{2}$ Two Holstein cows were omitted when analyzing counts per hour of behaviors because duration of standing estrus period $<0.002 \mathrm{~h}$ resulted in extreme outlier.

${ }^{3} P$-value for the test of difference between breeds.

${ }^{4}$ Mutual behaviors $=$ behaviors that were both initiated and received by the involved cows. 